II Sección: literatura y pensamiento

\title{
Lima Barreto: la ficción y la no ficción en «El Subterráneo del Cerro del Castillo»
}

\author{
Néfer Muñoz Solano \\ University of Dallas, United States \\ nmunozsolano@udallas.edu \\ https://orcid.org/0000-0002-3045-9176
}

Recibido: 8 de junio de 2020

Aceptado: 27 de setiembre de 2020

Resumen: Este trabajo pretende mostrar cómo el escritor brasileño Lima Barreto escribe la serie de crónicas «El subterráneo del Cerro del Castillo», un texto que mezcla la ficción con la no ficción, para oponerse disimuladamente a la reforma urbana, el mayor proyecto político, económico, social y cultural de Río de Janeiro a comienzos del siglo XX. En su texto, Lima Barreto legitima una leyenda de la existencia de tesoros escondidos debajo del Cerro del Castillo. Esta es una estrategia para atraer lectores $y$, al mismo tiempo, un artificio para filtrar "subterráneamente» sus propias opiniones sobre el valor simbólico de un lugar emblemático de la ciudad y, por extensión, sobre la riqueza de la topografía, la naturaleza, las tradiciones y la mezcla étnica de Río de Janeiro. Mientras la élite económica e intelectual de Brasil quería seguir un ideal europeo y estaba más interesada en «embellecer» el «exterior» urbano, demoliendo, aplanando y borrando su pasado, Lima Barreto se enfoca más bien en el «interior», en el valor profundo de la geografía, la memoria histórica y el mestizaje de la identidad carioca.

Palabras clave: Lima Barreto; Brasil; Río de Janeiro; literatura; periodismo; jesuitas.

\section{Lima Barreto: fiction and non-fiction in the chronicle series "O Subterrâneo do Morro do Castelo"}

\footnotetext{
(c) (1) (3)

La Revista Estudios es editada por la Universidad de Costa Rica y se distribuye bajo una Licencia Creative Commons Atribución-NoComercial-CompartirIgual 3.0 Costa Rica. Para más información envíe un mensaje a 
Abstract: This work explores how Lima Barreto writes O Subterrâneo do Morro do Castelo, a series of chronicles that mixes fiction and non-fiction, to surreptitiously oppose urban reform in Rio de Janeiro, the city's greatest socio-political, economic and cultural project of the early twentieth century. In his text, Lima Barreto legitimizes a legend about the existence of treasures hidden under the neighborhood, Morro do Castelo ("Castle Hill"). This strategy aims to attract readers, as well as assert his contested views on the symbolism of this emblematic place, and, by extension, the complexity of the city's rich topography, traditions, history, and miscegenation. While Brazil's economic and intellectual elite revered European ideals, striving to "beautify" the city's urban exterior by demolishing remnants of its past, Lima Barreto emphasizes the interior value of its geography, ethic mixing, and historical memory.

Keywords: Lima Barreto; Brazil; Rio de Janeiro; literature; journalism; jesuits.

\section{Introducción}

El Correio da Manhã, uno de los periódicos de más influencia de Río de Janeiro al comienzos del siglo XX, en su portada del viernes 28 de abril de 1905 publicó una noticia titulada «O Subterrâneo do Morro do Castelo» (en español, «El subterráneo del Cerro del Castillo»), la cual iba acompañada por un subtítulo sensacionalista que informaba sobre unas «Fabulosas riquezas». La noticia, publicada sin firma, retomaba una leyenda oral muy popular que había circulado por más de dos siglos en la ciudad, según la cual, había grandes fortunas enterradas en una serie de catacumbas secretas que serpenteaban por debajo de la entonces capital de Brasil. En 1905, Río de Janeiro vivía una intensa reforma urbana que el gobierno brasileño había emprendido para cambiar la estética de la ciudad con el fin de europeizarla y convertirla en una "París tropical" (Travancas, 2004, p. 175). Como parte de aquel proyecto, las autoridades estaban planeando la construcción de una nueva e imponente Avenida Central y, para lograrlo, tenían programado un plan detallado de demoliciones masivas en el centro de la metrópoli, no solamente de antiguos edificios coloniales, sino también de cerros enteros, como el emblemático «Morro do Castelo» («Cerro del Castillo», en español).

En la noticia, el Correio da Manhã informaba que durante los trabajos para demoler el cerro había sucedido algo imprevisto:

\section{(c) (i) (2)}

La Revista Estudios es editada por la Universidad de Costa Rica y se distribuye bajo una Licencia Creative Commons Atribución-NoComercial-CompartirIgual 3.0 Costa Rica. Para más información envíe un mensaje a 
Anteayer, al anochecer, había un gran ajetreo en el lugar de las obras. El grupo de trabajadores, a golpes arrítmicos, blandían los azadones contra aquel terreno de siglos, y con cada golpe, un bloque de tierra negra se removía y rodaba, desmoronándose por la pendiente natural del terreno trastocado.

En un momento dado, un trabajador llamado Nelson, al descargar su picareta sobre las últimas piedras de una base, notó con sorpresa que el terreno cedía, despejando la entrada a un vasto túnel (Lima Barreto, 1997, p. 3). ${ }^{\mathrm{i}}$

Con un tono inicialmente informativo, que más adelante muta hacia la especulación con rasgos literarios, en un vaivén entre la ficción y la no ficción, esta noticia daba cuenta del presunto descubrimiento de un subterráneo en el que supuestamente yacían grandes tesoros que habían sido escondidos siglos atrás por la Compañía de Jesús, la orden de los jesuitas. El texto describía cómo el ingeniero a cargo de las obras, Pedro Dutra, corrió a verificar lo que pasaba y comprobó que allí había un túnel de 1,6 metros de altura y medio metro de ancho. Debido al inesperado descubrimiento, los trabajos habían sido suspendidos y un centinela colocado a la entrada del presunto subterráneo, el cual, según advertía la crónica, albergaba o «una gran fortuna o una enorme broma de siglos» (Lima Barreto, 1997, p. 3).

La noticia recordaba que en el siglo XVIII los jesuitas, quienes habían acumulado grandes riquezas en diversas partes del mundo, habían sido expulsados de varios países europeos y se habían establecido en América. La orden de la Compañía de Jesús, según la leyenda, había construido debajo de su convento en el Cerro del Castillo un subterráneo, en el cual, ante su eventual expulsión de Brasil, habían depositado innumerables objetos de oro y plata de gran valor artístico, arcas con monedas y una opulenta biblioteca, que entre otros tesoros presuntamente contenía el archivo de la capitanía de Río de Janeiro y mapas de las minas del Amazonas. El texto del periódico explicaba que en el pasado se había emprendido varios proyectos de excavaciones para localizar los subterráneos, pero nunca se había encontrado nada, hasta ahora. El hallazgo de la supuesta entrada de una galería había provocado que al día siguiente un gran número de curiosos se

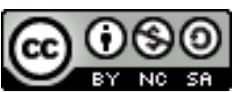

La Revista Estudios es editada por la Universidad de Costa Rica y se distribuye bajo una Licencia Creative Commons Atribución-NoComercial-CompartirIgual 3.0 Costa Rica. Para más información envíe un mensaje a revistaestudios.eeg@ucr.ac.cr. 
congregara en el lugar, al que también se hicieron presentes varios ingenieros de alto rango del proyecto de demolición y el propio Ministro de Hacienda de Brasil, quien, según decía la crónica con punzante ironía, estaba tan acostumbrado a «los perfumes del dinero» que todo hacía suponer que aquel sitio tenía «un aroma a caja fuerte» (Lima Barreto, 1997, p. 4).

El texto es muy efectivo para capturar la atención de los lectores ya que informa sobre un evento noticioso de interés, pero a la vez hurga en el pasado, incluyendo guiños literarios y trazos de sarcasmo. La noticia citaba a un experto, el llamado «Dr. Rocha Leão», quien creía que además de aquel subsuelo había otras grutas y conjeturaba dónde podrían estar ubicadas en la geografía carioca. ${ }^{i i}$ El texto del Correio da Manhã cerraba con la siguiente frase: «Por lo que pueden ver, aquí hay muchas cosas para los aficionados de la literatura fantástica y para los megalómanos, candidatos a un aposento en la Playa de la Saudade» (Lima Barreto, 1997, p. 5). iii Al llevar su propio texto al nivel de lo «fantástico» y lo «delirante»-ya que la megalomanía tiene que ver con la «manía de las grandezas» (Dicionário Priberam, 2020a) - el narrador anónimo de la crónica ponía en tela de duda su propia presunción sobre los subterráneos (porque en la Playa de la Saudade en aquel entonces había un famoso manicomio), pero reconocía que el hallazgo del túnel era una rica veta temática para explorar.

De hecho, esta noticia fue la primera entrega de lo que sería una serie de 26 crónicas publicadas entre el 28 de abril y el 6 de junio de 1905, en las que el autor anónimo excava los detalles de una leyenda popular al tiempo que escarba el pasado y los mitos fundacionales de la ciudad de Río de Janeiro y los emplea para oponerse, veladamente, al principal proyecto político, económico y social de la élite de aquel momento. Este, además, es un ejemplo textual de la hibridez entre la ficción y la no ficción publicada en periódicos, un fenómeno muy presente en la historia letrada de América Latina, principalmente a través de la figura del «escritor periodista». Esta figura, la del escritor que trabaja en salas de redacción, origina un fenómeno escriturario de doble vía, ya que novela (ficcionaliza) en los periódicos y 
reportea en las novelas. Es decir, estos escritores incluyen elementos ficcionales en sus notas periodísticas y, al mismo tiempo, recaban información y datos que más tarde emplean para escribir sus ficciones.

Décadas más tarde de la publicación de aquellas crónicas en el Correio da Manhã, la investigadora Beatriz Resende comprobó que el autor de la serie sin firma era Afonso Henríquez de Lima Barreto, uno de los escritores canónicos más prominentes de Brasil. ${ }^{i v}$ Resende considera a Lima Barreto como un «antropólogo de lo cotidiano", una especie de etnógrafo que escribe sobre temas no sacralizados (1993, p. 20). Eliane Vasconcellos Leitão explica que en este escritor hay un emborronamiento de límites, ya que su ficción quiere ser crónica y su crónica parece aspirar a la ficción (2001, p. 12). La crítica Lilia Moritz Schwarcz lo describe como una figura compleja y ambivalente, quien batalla por la autonomía de su escritura, pero se siente inadaptado e incapacitado por su condición social y étnica (2010, p. 16), ya que Lima Barreto era mulato y de clase obrera. Para el historiador Nicolau Sevcenko, este es un escritor con una visión estética que concibe a la «literatura como misión» (2003, p. 193) y al periodismo como una vía no solo para informar a los lectores sino también para crear nuevas necesidades y promover en el público la acción, algo que Gramsci denominaba «periodismo integral» (1999, p. 159). Es decir, los textos de Lima Barreto conforman una escritura híbrida que zigzaguea entre la ficción y no ficción, al mismo tiempo que es una obra de compromiso y militancia para influir en los lectores y promover cambios sociales.

Durante el siglo XX, muchos de los principales literatos brasileños están ligados a salas de redacción. Lima Barreto, João do Rio, Graciliano Ramos, Carlos Drummond de Andrade, Nelson Rodrigues y Jorge Amado son apenas algunos ejemplos de esta figura literaria del «escritor periodista» latinoamericano. En sus obras se encuentra lo que el crítico Aníbal González llama el «disimulo», una estrategia narrativa en la que hay una imitación mutua de textos y discursos, solapando lo que se quiere decir, en un vaivén entre el deseo de expresar y la necesidad de ocultar, recurriendo a un «manto de invisibilidad» para ejercer

\section{(C) 100}

La Revista Estudios es editada por la Universidad de Costa Rica y se distribuye bajo una Licencia Creative Commons Atribución-NoComercial-CompartirIgual 3.0 Costa Rica. Para más información envíe un mensaje a 
resistencia o evitar la censura (2006, p. 241). Muchos de estos «escritores periodistas» disimulan o encubren sus críticas y opiniones a través de un género que mezcla discursos, la crónica.

Este trabajo pretende mostrar cómo Lima Barreto escribe la serie de crónicas El subterráneo del Cerro del Castillo, un texto que mezcla la ficción con la no ficción, para oponerse disimuladamente a la reforma urbana, el mayor proyecto político, económico, social y cultural de Río de Janeiro a comienzos del siglo XX. En su texto, Lima Barreto legitima una leyenda de la existencia de tesoros escondidos debajo del Cerro del Castillo. Esta es una estrategia para atraer lectores y, al mismo tiempo, un artificio para filtrar «subterráneamente» sus propias opiniones sobre el valor simbólico de un lugar emblemático de la ciudad y, por extensión, sobre la riqueza de la topografía, las tradiciones, los contornos, las imperfecciones y el mestizaje de Río de Janeiro. Mientras la élite económica e intelectual de Brasil quería seguir un ideal europeo y estaba más interesada en «embellecer» el «exterior» urbano demoliendo, aplanando y borrando su pasado-, Lima Barreto cree que el tesoro no está en una fachada europea sino en las profundas raíces de las manifestaciones diversas de la ciudad, por eso se enfoca más bien en el «interior» y emprende una operación para escarbar, redescubrir, rescatar y reivindicar el profundo valor de la geografía, la memoria histórica y la identidad mestiza de la urbe.

\section{La «regeneración»: París en el trópico}

La historia de Río de Janeiro está poblada por acontecimientos inusuales y dramáticos. La bahía donde se encuentra lo que hoy es esta ciudad fue descubierta por un grupo de navíos portugueses al mando del italiano Américo Vespucio el 1 de enero de 1502. Los exploradores pensaron que aquel paisaje espectacular de aguas calmadas, cerros empinados y exuberante vegetación era la desembocadura de un río. Como el día del descubrimiento era un primero de enero, decidieron llamar a aquel lugar «Rio de Janeiro» (Arciniegas, 2002, p. 328), que en español significa «Río de Enero». En 1565, después de la expulsión de un grupo de franceses que

\section{(c) (i) (2)}

La Revista Estudios es editada por la Universidad de Costa Rica y se distribuye bajo una Licencia Creative Commons Atribución-NoComercial-CompartirIgual 3.0 Costa Rica. Para más información envíe un mensaje a 
se habían establecido, allí los portugueses fundaron allí el primer asentamiento lusitano, bautizado oficialmente con el nombre de «San Sebastián de Río de Janeiro».

Dos años después de la fundación, el entonces gobernador general de Brasil, Mem de Sá, decidió reinstalar la sede oficial del gobierno en el «Morro de São Januário» («Cerro de San Genaro» en español), más tarde conocido como «Morro do Castelo» («Cerro del Castillo»). La elección de aquel punto era estratégica para la defensa de la ciudad. Porque, en caso de posibles ataques, desde ahí se tenía una clara visibilidad de la Bahía de Guanabara. El Cerro del Castillo tenía 63 metros de altura y ocupaba un área de 184 mil metros cuadrados (Barros, 2002, párr. 7). En ese espacio, originalmente fortificado y amurallado, se construyeron la Casa del Gobernador, el Palacio Municipal, la prisión, almacenes, el Colegio de los Jesuitas y varias iglesias. Y a partir de aquel lugar comenzó el crecimiento exponencial que en los siglos siguientes tendría San Sebastián de Río de Janeiro.

En los anales de la ciudad, uno de los acontecimientos más inusuales de la historia de la ciudad se dio en el año 1807, cuando Napoleón Bonaparte ordenó la invasión de Portugal y provocó que la corte portuguesa, escoltada por la armada británica, tuviera que huir de Lisboa. De manera que una monarquía europea se vio empujada a cruzar el Atlántico y, repentinamente, asentarse en Río de Janeiro. Esta era una situación inédita en los anales de la historia mundial, pues un pueblo colonial pasó a convertirse súbitamente en el centro y la sede de un imperio, el «Reino Unido de Portugal, Brasil y Algarve»: el repentino cambio de estatus promovió una serie de aceleradas transformaciones en la configuración política, económica, social y cultural de la ciudad (Wasserman, 2011, p. 46).

Más tarde, Brasil adquirió su independencia en 1822, cuando Pedro I firmó una proclama nombrándose a sí mismo emperador, con lo cual reafirmó la importancia de Río de Janeiro como sede imperial. De este modo, empezó un período de monarquía parlamentaria que se extendió durante buena parte del siglo XIX y concluyó con la declaratoria de la República, el 15 de noviembre de 1889. En

\section{(c) (i) (2)}

La Revista Estudios es editada por la Universidad de Costa Rica y se distribuye bajo una Licencia Creative Commons Atribución-NoComercial-CompartirIgual 3.0 Costa Rica. Para más información envíe un mensaje a 
su niñez, Lima Barreto presenció esta mudanza hacia el sistema republicano y, más tarde, en varios de sus textos periodísticos y literarios expresaría su nostalgia por los tiempos de la monarquía. De hecho, calificaba aquella transición hacia la república como «una rematada tontería» (Coisas do reino do Jambon 110). v

En muchos de sus escritos, Lima Barreto muestra una añoranza por el antiguo sistema monárquico, mientras que en otros manifiesta una abierta simpatía por el anarquismo, lo que pareciera una marcada contradicción, sin embargo, el crítico y biógrafo Francisco de Assis Barbosa no la considera una discordancia, ya que los impulsores de la república eran, a los ojos del escritor, miembros de una plutocracia, más conservadores que los propios aristócratas monárquicos (2003, p. 17). El escritor opinaba que, paradójicamente, la caída de los «monárquicos» representaba el derrumbamiento de los «liberales», ya que (a pesar de la nomenclatura, en un claro trastrocamiento de roles) el ascenso de los «republicanos» llevó al poder a una nueva élite que era aún más «conservadora» que la que gobernaba previamente.

Al perder el poder el viejo patriarcado del imperio, las riendas de Brasil fueron asumidas entonces por una nueva élite republicana, conocida como «los arribistas» (Sevcenko, 2003, p. 56). Este es un grupo conformado primordialmente por las oligarquías de los barones cafetaleros de São Paulo y los acaudalados productores de leche de Minas Gerais, quienes se aliaron y se alternaron la presidencia y los principales puestos políticos, articulando un fenómeno que en la historia brasileña es conocido como la «política del café con leche» (Meade, 2010, p. 123). Este período de la llamada «Primera República» comienza a fines del siglo XIX y se extiende durante las primeras tres décadas del siglo XX, un momento histórico de Belle Époque en Brasil, que coincide con los años en que Lima Barreto desarrolla su obra y durante los cuales el país vive un violento conservadurismo social (Aidoo \& Silva, 2013, p. 2).

\section{(c) (i) (2)}

La Revista Estudios es editada por la Universidad de Costa Rica y se distribuye bajo una Licencia Creative Commons Atribución-NoComercial-CompartirIgual 3.0 Costa Rica. Para más información envíe un mensaje a 
El comienzo del siglo XX es una época de gran crecimiento económico y comercial en Río de Janeiro. Al igual que otras ciudades que eran capitales y puertos -como Buenos Aires, Montevideo, La Habana y la Ciudad de Panamá-, Río pasó por un intenso proceso de prosperidad y transformación (Romero, 1999, p. 299).vi Sin embargo, a pesar de su boom económico, comercial y poblacional, al comienzo del siglo $\mathrm{XX}$ es una urbe insegura y con serios problemas sanitarios, con constantes epidemias de varicela, viruela, tuberculosis, malaria, lepra y fiebre amarilla, lo que le hizo ganarse el mote de «la capital de la muerte» (Prefeitura da cidade do Rio de Janeiro, 2006, pp. 5-8).

La nueva élite republicana brasileña comienza a mirar de reojo a otras ciudades americanas que también estaban en auge, como Buenos Aires y Nueva York, al tiempo que profesa un interés por darle un aire europeo a su propia capital. El escritor Olavo Bilac, ferviente partidario de los republicanos y uno de los intelectuales brasileños más influyentes de esta época, afirmaba que Río de Janeiro debía cambiar su estética: «Pero justamente porque tanto te ama, es que tu hijo debe tener el derecho de decirte, entre dos besos, que la vecina Buenos Aires es una vergüenza para ti, adorada Sebastianópolis» (1900, p. 2). vii Años más tarde, Lima Barreto criticaría tanto en sus novelas y cuentos como en sus notas periodísticas esa envidia hacia la vecina argentina, calificándola como algo «imbécil» (1909, p. 204), ya que veía fuertes visos de racismo en ese anhelo por querer europeizar la estética urbana de Río, al mismo tiempo que se ignoraba la realidad y la historia negra de la ciudad (2004b, p. 166).

Con el fin de encabezar un plan de reforma urbana, en 1902, el entonces presidente de Brasil, Francisco Rodrigues Alves, nombró como alcalde de Río de Janeiro a Francisco Pereira Passos, a quien le encargó la tarea impulsar una masiva transformación portuaria y arquitectónica. Ingeniero de profesión y miembro de una acaudalada familia, Pereira Passos había vivido en su juventud en Francia donde participó en la construcción de obras públicas y atestiguó de primera mano el proceso de reforma urbana de París, llevada a cabo por Georges-Eugène 
Haussmann. viii El nombramiento de Pereira Passos fue recibido con entusiasmo por diversos sectores de la élite y el influyente diario Correio da Manhã le hizo una solicitud especial: «la transformación de la ciudad de Río de Janeiro, para que no continúe avergonzándonos y deprimiéndonos cuando la comparamos con otras ciudades» (O Rio de Janeiro de Pereira Passos, 1985, p. 20).

Uno de los primeros pasos en el proceso de reforma fue la firma de un préstamo con bancos ingleses para financiar la modernización del puerto y la construcción de obras públicas monumentales, entre las que se proyectaba una nueva Avenida Central. Seguidamente, se promulgó una ley de expropiaciones que le otorgó amplios poderes al alcalde Pereira Passos, quien, en medio de grandes polémicas, emprendió un plan de demoliciones masivas de antiguos edificios coloniales, muchos de los cuales eran habitados en hacinamiento por personas pobres y eran conocidos bajo el nombre de «cortiços". En Río de Janeiro, aquel proceso de demoliciones comenzó a ser conocido popularmente como «o botaabaixo» («el tira abajo»). ix Al describir el comienzo del «bota-abaixo», el escritor Olavo Bilac festejaba el inicio de una nueva era y decía que en la ciudad se escuchaba un lamento, el gemido del «Pasado, del Atraso, del Oprobio», el sollozo de la "ciudad colonial, inmunda, retrógrada, atascada en sus viejas tradiciones» (2002, p. 353). ${ }^{x}$ Es decir, la nueva élite construye un mensaje en el que se asocia a la república con el futuro, la modernidad, la sofisticación y el progreso, mientras que la monarquía es ligada con el pasado, la suciedad, el atraso y lo obsoleto.

En sus dos primeros años de gestión, Pereira Passos sacrificó a más de 20 mil perros callejeros, prohibió el pedir limosna en las calles, eliminó los criaderos de cerdos en la ciudad y prohibió que las personas fueran colgadas de los tranvías y escupieran en los vagones. Su plan incluía también demoler cerros enteros, ya que se creía que estos accidentes geográficos atentaban contra la salud pública al impedir la circulación del aire (Kessel, 2008, p. 36). .i El Cerro del Castillo, según el proyecto, debía ser demolido también porque era un obstáculo en el trazado de la nueva Avenida Central. Además, con la demolición de cerros se planeaba aterrar el 
mar para ganar espacio de construcción en tierra firme. Pero tal vez uno de los puntos centrales es que uno de los objetivos de las demoliciones era desalojar del centro de la ciudad a la población pobre, quien vivía «en la mayor incomodidad, inmundicia y promiscuidad, lista para erigir barricadas en los estrechos callejones del centro al primer grito de motín» (Sevcenko, 2003, p. 41). xii La operación de reforma no fue solo entonces arquitectónica, sino también, meticulosamente, demográfica, económica, social y cultural, ya que se comenzó a desplazar y a ocultar a la pobreza que hasta entonces estaba muy visible en el corazón mismo de la capital.

En estos años, uno de los periódicos de Río de Janeiro, la Gazeta de Notícias, publicaba una reconocida columna que se titulaba Binóculo, un espacio pionero de la crónica social y de espectáculos en Brasil. El autor de aquella columna era un periodista llamado Figueiredo Pimentel, quien comentaba noticias de modas y promovía costumbres que consideraba elegantes -como el hábito de tomar el té a las cinco de la tarde, la organización de exposiciones caninas y las actividades del Ladies Club-. Figuereido Pimental llegó a popularizar ampliamente dos términos: el uso del vocablo «smart», para denotar todo lo que fuera «chic», y la frase «O Rio civiliza-se» (en español «Río se civiliza»), que se convirtió en todo un lema de respaldo para el proyecto de Pereira Passos (Sevcenko, 2003, p. 54).

Lima Barreto llegó llamar a Figueiredo Pimentel, a sus seguidores y a sus continuadores los «idiotas binoculares» y se preguntaba por qué un periódico importante de la ciudad tenía que darle espacio a temas ligeros, como por ejemplo, enseñar a las personas cómo vestir los guantes con elegancia, lo que para él eran simplemente «bobagens» («boberías», en español) (2005b, p. 265). xiii El crítico Renato Cordeiro Gomes sostiene que la reforma urbana fue el montaje de una nueva escenografía, la creación de un escenario ilusionista. Río «se civilizaba» bajo el patrocinio del poder, era una mudanza en la esfera física material y también en la simbólica, en el orden de los signos (Gomes, 2008, pp. 113-116). El nuevo escenario creaba una aspiración, un ideal que, sin embargo, no siempre concordaba 
con la ciudad real que enfrentaban la mayoría de los cariocas, de clase media y obrera.

El alcalde Pereira Passos paulatinamente se arroja triunfos políticos al llevar a cabo las demoliciones, expulsar a la población pobre del casco central, ampliar y alargar las principales arterias viales de la ciudad y, sobre todo, construir la tan ansiada nueva Avenida Central, a lo largo de la cual se comenzaron a perfilar una serie de edificios de arquitectura europea, como el espectacular Teatro Municipal, cuya estructura metálica fue importada en su totalidad de Europa y fue descrita en su momento como más rica que la propia Ópera de París (Abreu 63). En uno de sus escritos, Lima Barreto criticaría cómo el nuevo Teatro Municipal estaba vedado a la mayoría, ya que una persona de clase obrera, si quisiera asistir a un espectáculo, tendría que gastar solo en vestuario el ingreso económico de meses de su familia (2005a, p. 128). Sin embargo, en periódicos, revistas, cafés y lugares públicos, la élite celebró el proceso liderado por Pereira Passos, quien comenzó a ser conocido como el «Haussmann tropical» y su proceso de reforma es llamada -y conceptualizada como- «a regeneração» («la regeneración», en español) (Benchimol, 1990, p. 228).

En portugués, la palabra «regeneração» es restablecer algo «que estaba destruido» o el emprendimiento de «una reforma moral», mientras que el verbo «regenerar» es «dar una nueva existencia» y tiene que ver con las palabras «mejorar», «restaurar», «corregir» 0 «enmendar» (Dicionário Priberam, 2020c). La regeneración implicaba entonces, ideológicamente, que algo había estado mal o se había degenerado y, por lo tanto, necesitaba de una corrección. En la narrativa creada para la reforma urbana, el concepto de «regeneración» de Pereira Passos fue asociado directamente con el verbo «embellecer», xiv una palabra que es empleada y repetida constantemente. Es decir, la «regeneración» tenía implicaciones directa y aparentemente estéticas, pero al desplazar a la población pobre, la mayoría de los cuales eran afrodescendientes y mestizos, en el fondo las implicaciones eran también éticas, raciales, culturales y de clase.

\section{(c) (1) 8 ()}

La Revista Estudios es editada por la Universidad de Costa Rica y se distribuye bajo una Licencia Creative Commons Atribución-NoComercial-CompartirIgual 3.0 Costa Rica. Para más información envíe un mensaje a 
La «regeneración» de la república brasileña pretendía arrasar, física y simbólicamente, no solo con la monarquía, sino también con todo lo antiguo y lo vernáculo. Entonces, la república, como baluarte de lo «moderno» ejerció su imposición sobre el anterior sistema de gobierno, intentando borrar todos sus vestigios y de paso, ejecutando una especie de operación «quirúrgica» para «demoler», "aplastar» y «desechar» los relieves de una ciudad diversa y una sociedad multicultural para procurar presentar un paisaje uniformemente europeo. Lima Barreto cree que ante las piquetas que excavan y destruyen el Cerro del Castillo y los antiguos edificios coloniales subyacía un pasado inestimable, rico en diferencias y contradicciones, que era necesario mantener y por el cual había que luchar. En su proceso escriturario de resistencia, el cronista, solapadamente, recurrió a un mecanismo subterráneo, con el cual pretendía despertar en los lectores la consciencia sobre la trascendencia de la memoria histórica y el valor del mestizaje y lo popular.

\section{La crónica híbrida}

El sábado 29 de abril de 1905 el periódico Correio da Manhã publicó la segunda entrega de su serie sobre los subterráneos del Cerro del Castillo. En este segundo texto, el periodista acude al lugar del hallazgo, donde han tenido que levantar una valla de alambre para contener a los curiosos. En el sitio de las excavaciones entrevista al ingeniero encargado de las obras, Pedro Dutra, con quien mantiene este intercambio:

-Entonces, ¿ya encontraron a los apóstoles?

- ¿Cuáles apóstoles?

- ¿Los de oro, con ojos esmeralda?

- Por el momento no, nos contestó el ingeniero con una sonrisa y amablemente nos acompañó a la puerta del túnel.

El túnel es alto, de 1 metro y 90 centímetros, unos 80 centímetros de ancho. Al interior, los trabajadores retiraban el barro blando y pegajoso, que se acumulaba hasta la mitad de las espinillas. En el fondo había una pequeña luz parpadeante, colocada allí para facilitar la limpieza del subsuelo.

Un escenario tétrico de un gran drama (Lima Barreto, 1997, p. 8). ${ }^{\mathrm{xv}}$

\section{(c) (i) (9) (2)}

La Revista Estudios es editada por la Universidad de Costa Rica y se distribuye bajo una Licencia Creative Commons Atribución-NoComercial-CompartirIgual 3.0 Costa Rica. Para más información envíe un mensaje a 
Aquí se nota cómo Lima Barreto, con entonces 24 años, hace una operación que es típica de la naciente profesión del «reporter» y del periodismo moderno que se comienza a practicar en distintas ciudades de América Latina: acudir en persona al lugar de la noticia, interrogar directamente a los involucrados y construir una narrativa con abundancia de datos y detalles. Es una manera de hacer que los lectores se sientan ahí, vicariamente, representados por el periodista. El «reporter» es entonces una nueva versión del «flâneur», quien como aquella figura decimonónica recorre las ciudades, pero con la diferencia que no vaga sin rumbo por un mero placer estético, sino más bien que va a lugares específicos para escribir una noticia, una figura que la crítica Vivianne Mahieux denomina un «flâneur con salario» (2011, p. 42).

En la entrevista, el periodista lanza un anzuelo que pretende capturar la atención de los lectores, la supuesta existencia de unas estatuas, «apóstoles de oro» con ojos de esmeralda. Este es un «cebo» que forma parte de un artificio sensacionalista, que pretende estimular el interés por la crónica y, a la vez, reforzar una idea verosímil en los lectores: debajo del Cerro del Castillo hay un tesoro valioso. No es una casualidad que el narrador anuncie que aquel es el «escenario tétrico de un gran drama», ya que precisamente está creando el escenario o la atmósfera narrativa para su historia, que más adelante tendrá un giro dramático y sangriento. El escritor -al igual que otros artistas- está en medio de su proceso creativo, algo que el filósofo Nelson Goodman llama «worldmaking» o «creación de mundos» (1978, p. 94).

En las siguientes entregas, el narrador informa que el propio presidente de Brasil visitó el sitio de las excavaciones, califica al lugar de los subterráneos como un «moderno El Dorado» y anuncia que los ingenieros han encontrado un nuevo túnel, cuyas paredes eran de ladrillo. De hecho, para reforzar la veracidad de su relato, afirma que ha llevado al periódico parte de uno de aquellos ladrillos del subterráneo, que ahora está expuesto en la sala de redacción para todo quien quiera ir a examinarlo (Lima Barreto, 1997, p. 14). Es decir, hasta este momento, el 
ISSN 1659-3316

«escritor periodista» ha tenido el cuidado de construir una narrativa con un énfasis en datos y evidencias verificables.

Sin embargo, la serie comienza a inclinarse más hacia la ficción a partir de la quinta entrega. Es allí cuando el narrador introduce en su relato a un personaje llamado el «señor Coelho», un hombre a quien conoce casualmente entre los curiosos arremolinados tras la valla de alambre. El señor Coelho, quien asegura que él posee papeles antiguos de primera mano, le dice al periodista que aquellos túneles que están excavando las autoridades fueron construidos por los jesuitas para confundir a eventuales cazadores de fortunas, porque las galerías que estaban abarrotadas de riquezas se encontraban en otro punto, a 430 metros del pie del cerro, donde el aire era casi irrespirable debido a emanaciones sulfúricas (Lima Barreto, 1997, p. 15). El periodista entonces le pregunta si podría ver aquellos documentos, a lo que el hombre accede y lo cita en su casa para mostrárselos. Aquí el narrador frena el relato y anuncia que los lectores tendrán más detalles en la edición del día siguiente.

Este recurso es algo que Lima Barreto hará a lo largo de la serie, crear expectativas, cortar la narración y anunciar que continuará el relato en la próxima crónica. «Mañana contaremos a los lectores esta bizarra y maravillosa historia» (Lima Barreto, 1997, p. 28). xvi Esta es una de las variaciones de la frase que incluye en diferentes entregas. Esta técnica tiene un propósito doble, tanto narrativo como comercial, ya que, por un lado, incrementa la atracción por el relato y, por el otro, incentiva a que los lectores compren el ejemplar del día siguiente. Esta es una característica propia de la literatura de folletín, que la crítica Marlyse Meyer define como una ficción «en rebanadas» (1996, p. 417). xvii La serie El subterráneo del Cerro del Castillo es un folletín híbrido, ya que mezcla una noticia de actualidad con una narración novelesca, manteniendo un constante zigzagueo entre la ficción y la no ficción. En todo caso, el Correio da Manhã nunca anunció que estas crónicas tenían, al menos en parte, una naturaleza ficcional y siempre las imprimió al lado de otras

\section{(c) (i) (-)}

La Revista Estudios es editada por la Universidad de Costa Rica y se distribuye bajo una Licencia Creative Commons Atribución-NoComercial-CompartirIgual 3.0 Costa Rica. Para más información envíe un mensaje a 
noticias locales e internacionales de 1905, por ejemplo, los problemas de vivienda de Río de Janeiro o la revolución rusa.

En la sexta entrega de la serie, el periodista narra cómo, en medio de una lluvia torrencial, toma un tranvía para ir al barrio de Gamboa en busca de la casa del señor Coelho, a quien describe como un hombre «alto», de «bigotes grises» y «mirada penetrante» (Lima Barreto, 1997, p. 15). Tras caminar por una escarpada ladera, en medio de una «oscuridad tenebrosa», y preguntar a varios vecinos, finalmente logra localizar la modesta vivienda de su fuente, de quien revela es un empleado público. Una vez adentro, nota cómo en las paredes hay dos retratos, uno del francés «Allan Kardec», una figura importante del espiritismo, y otro del portugués Sebastián José de Carvalho, el «Marqués de Pombal», quien fue la autoridad política portuguesa que en el siglo XVIII ordenó la expulsión de los jesuitas de Brasil (Moreira, 2013, p. 101).De esta manera, el narrador introduce en el texto dos referencias comunes de aquella época, una de la cultura popular y la otra de la historiografía de Brasil.

El anfitrión se lamenta que el periodista haya tenido que ir a su casa aquella noche «con esta lluvia», a lo que el cronista le responde que «es necesario informar» porque «el público es exigente» y el señor Coelho es la persona capaz de «satisfacer la curiosidad carioca» (Lima Barreto, 1997, p. 20). Es así como el periodista enfatiza su misión de servicio público y se reviste a sí mismo con un aura de detective. Es decir, dramatiza la búsqueda del tesoro oculto y celebra el proceso de exploración, con el que va a emprender una investigación del pasado y la memoria histórica de la ciudad.

En la entrevista, el señor Coelho le explica al periodista que todos los subterráneos del Cerro del Castillo fueron construidos en el siglo XVIII, en tiempos del Marqués de Pombal. Y aquí el cronista aprovecha para dar un poco de contexto histórico: en el año 1710, a petición del rey de Francia, el corsario francés JeanFrançois Duclerc invadió a la colonia portuguesa de Río de Janeiro, entonces una colonia portuguesa. Pero el invasor galo fue derrotado en su empresa por los 
portugueses y poco después murió misteriosamente. Temiendo una arremetida de los franceses, quienes querrían vengar a su compatriota y, de paso, saquear la ciudad, los jesuitas -presuntamente- decidieron esconder sus riquezas en los subterráneos. El señor Coelho le muestra al narrador una serie de pergaminos, que son descritos como «amarillentos» y con «aroma a antiguo» (Lima Barreto, 1997, p. 20). Uno de ellos es un acta en latín, que el periodista reproduce para sus lectores en portugués, convirtiéndose, implícitamente en la narración, en un traductor. En aquella acta se detallan las riquezas depositadas en los subterráneos: imágenes de oro macizo de San Sebastián, San José, la virgen María y San Ignacio de Loyola (fundador de la Compañía de Jesús), 1400 barras de oro, así como numerosas arcas con oro en polvo, monedas, diamantes y otras piedras preciosas valoradas en millones (Lima Barreto, 1997, p. 23).

Según el señor Coelho, el tesoro nunca fue extraído de los subterráneos porque cuando los jesuitas fueron expulsados de Brasil, en 1759, tras la decisión del Marqués de Pombal, las autoridades portuguesas detuvieron a los sacerdotes, vigilaron férreamente los edificios de la Compañía de Jesús y, cuando hicieron un recuento de los bienes, se encontraron con una suma muy baja, a pesar de que era ampliamente conocido que tenían posesiones opulentas. En este intercambio entre cronista y fuente, el señor Coelho hace una revelación que probablemente asombró a los lectores de aquella época, cuando afirma que Paulo de Frontin, la mano derecha del alcalde Pereira Passos en la reforma urbana, era una reencarnación del Marqués de Pombal.

Sin ofrecer más pruebas que su propio testimonio, el señor Coelho describe una supuesta sesión espiritista a la que Frontin había asistido, en la cual un espíritu le reveló, a través de un médium, que para pagar las penas de su vida pasada, el Marqués de Pombal, había regresado al mundo y él (Frontin) era su reencarnación. Ante esta noticia, el narrador de las crónicas opina que «era justísimo que [Pombal/Frontin], en una segunda reencarnación, reparase el mal [que hizo en su

\section{(c) (i) (2)}

La Revista Estudios es editada por la Universidad de Costa Rica y se distribuye bajo una Licencia Creative Commons Atribución-NoComercial-CompartirIgual 3.0 Costa Rica. Para más información envíe un mensaje a 
vida pasada al expulsar a los jesuitas], descubriendo los tesoros ocultos y distribuyendolos entre los pobres» (Lima Barreto, 1997, p. 31).

Este pasaje es clave para el análisis del texto porque el «periodista escritor» claramente está novelando personajes y eventos de la vida real de Río de Janeiro. «Allan Kardec», el "Marqués de Pombal», "Jean-François Duclerc» y «Paulo de Frontin» eran todos personajes reales presentes en la historiografía o en el imaginario de los lectores de la época, mientras que el "señor Coelho", sus documentos y la sesión espiritista forman parte del universo ficcional del narrador. Es lo que el crítico y escritor Tomás Eloy Martínez llama «efecto de contigüidad», el fenómeno que sucede cuando el discurso periodístico se yuxtapone al ficcional y se genera un proceso de "ósmosis», en el cual se hace difícil distinguir la verdad verificable de lo ficcional, y genera que al final todo quede impregnado de verdad (2004, p. 41).

El propio Lima Barreto escribiría en un texto posterior que «Los géneros que heredamos y que creamos están a toda hora entrelazándose, injertándose, para variar y atraerse» (1956b, p. 116). Es decir, este autor experimenta, entrelaza, injerta e imbrica los datos e información periodística con su propia inventiva, en un fenómeno fluido de intercambios de doble vía entre periodismo y literatura. Este proceso de ficcionalización probablemente creó confusión en los lectores de la época, pero es muy posible que también sedujo y promovió el interés por la serie, ya que el Correio da Manhã le dio el visto bueno a Lima Barreto para que prosiguiera con las entregas por un mes más. En este pasaje también se nota lo que en portugués se denomina el «engajamento» del autor (en español, el «compromiso» del autor). Insinuar que Frontin iba a dar el tesoro a los pobres, más que una sugerencia ingenua era una forma de presión indirecta y es uno de los múltiples ejemplos de cómo la obra de Lima Barreto es «engajada» («comprometida»), ya que, como lo explica la crítica Isabel Travancas, uno de sus temas recurrentes es la militancia activa por las causas de la justicia social (2004a, p. 8).

\footnotetext{
(c) (i)(2)

La Revista Estudios es editada por la Universidad de Costa Rica y se distribuye bajo una Licencia Creative Commons Atribución-NoComercial-CompartirIgual 3.0 Costa Rica. Para más información envíe un mensaje a revistaestudios.eeg@ucr.ac.cr.
} 
A partir de la entrega nueve, la serie incluye la parte más acentuadamente ficcional de las crónicas. En esa novena crónica, el narrador revela que uno de los documentos del señor Coelho es un antiguo códice del siglo XVIII, manuscrito en italiano probablemente por un jesuita. Según el narrador de la crónica, él va a ofrecer a sus lectores una traducción al portugués moderno en la cual ha conservado el tono original, pero omitiendo los matices arcaicos. Agrega que aquel códice había sido originalmente escrito con una tinta indeleble «tal vez negra», pero que con el tiempo «tomó un tono rojo sobre el papel amarillento». Con ese detalle, el «tono rojo» con el que está escrita la historia, el narrador está anticipando lo que vendrá, una serie de eventos sangrientos.

El códice italiano es una historia de amor, traición y muerte que se desarrolla en el Cerro del Castillo y se titula «Doña Garza». Este relato lleva el siguiente subtítulo: «O lo que pasó a mediados del siglo XVIII en los subterráneos de los padres de la Compañía de Jesús, en la ciudad de San Sebastián de Río de Janeiro, la muy heroica, con ocasión de la primera invasión de los franceses a cargo de Duclerc» (Lima Barreto, 1997, p. 36).xviii Este largo subtítulo evoca a las «cartas de relación» de la época colonial, que tenían un propósito de relato o informe a la corona (Mignolo, 1987, p. 70). Es decir, para reforzar la veracidad del supuesto códice y reforzar la verosimilitud, Lima Barreto tiene el cuidado de enmascarar el texto con la apariencia de un género colonial.

En las próximas entregas, en un juego de espacios y tiempos, la serie alterna entre el contenido del manuscrito de «Doña Garza»-un texto que es ficcional- y los avances de las excavaciones del Cerro del Castillo, -que eran la parte informativa de la serie-, es decir, el relato se mueve entre noticia y novela. De manera que hay momentos en que la ficción desplaza completamente al reportaje y, en otros, en que el reportaje regresa y desplaza a la ficción, en un vaivén donde hay traslapes y zonas de contacto. Es una oscilación entre el pasado (el año 1710) y el presente de los lectores de la crónica (el año 1905), el cual, a su vez, para los lectores contemporáneos, es un nuevo pasado. Es una imbricación (o mestizaje) de géneros, 
donde hay matices de noticia, entretenimiento, sensacionalismo, historia y un sutil mensaje subterráneo de resistencia. Es un texto enmarcado dentro de otro texto, donde el narrador se presenta no como autor sino apenas como «lector»y «traductor», es decir, como un intermediario, empleando una estrategia narrativa de larga data en la literatura, como en el Quijote de Cervantes.

El manuscrito italiano, que el narrador describe como un viejo «palimpsesto», cuenta la historia de Aida de Lambertini, una condesa florentina de gran belleza, siempre vestida elegantemente de blanco, conocida como «Doña Garza». La historia relata cómo durante un viaje hacia Francia, unos piratas de Argel secuestran el barco en el cual viajaba y asesinan a todos pasajeros y la tripulación, excepto a Doña Garza, quien se convierte en la única sobreviviente y prisionera de los piratas. Sin embargo, más tarde la noble italiana es rescatada por la Compañía de Jesús, que la traslada a vivir a Río de Janeiro. Una vez en Brasil, la condesa vive en una casa del Cerro del Castillo y figura como la esposa de Martim Gonçalves Albernaz, un burócrata portugués que tenía un futuro promisorio en los rangos de la corona, pero que cayó en desgracia a los ojos del rey de Portugal.

En la crónica se narra cómo en la alcoba de la condesa, detrás de un armario, hay una entrada secreta, la cual conduce a una serie de túneles y pasadizos que atraviesan subterráneamente la ciudad. Esa entrada clandestina es usada por un jesuita, el francés Jean de Jouquières, Marqués de Fressenec, quien es el amante de Doña Garza. Este sacerdote aristócrata tiene una licencia especial de su orden para «experimentar las groserías del mundo» (Lima Barreto, 1997, p. 54). En uno de sus encuentros furtivos, Jouquières le cuenta a la condesa que ha recibido noticias de que el rey de Francia está planeando enviar un grupo de navíos para invadir a Río de Janeiro. La expedición va a ser comandada por Jean-François Duclerc, un corsario francés nacido en la isla de Guadalupe, a quien el jesuita se refiere despectivamente como «o crioulo» («el criollo») (Lima Barreto, 1997, p. 47).

\footnotetext{
(ब) (1)

La Revista Estudios es editada por la Universidad de Costa Rica y se distribuye bajo una Licencia Creative Commons Atribución-NoComercial-CompartirIgual 3.0 Costa Rica. Para más información envíe un mensaje a revistaestudios.eeg@ucr.ac.cr.
} 
Ante la zozobra de la invasión y el temor al saqueo, los jesuitas deciden entonces esconder sus riquezas en los fondos de los túneles secretos. xix Por eso se trasladan hasta las catacumbas repletas con tesoros y luego destruyen las entradas de las galerías. Tras esta operación, el padre Jouquières recibe una importante misión: viajar al norte de Brasil como líder de una exploración jesuita para recoger el oro que han encontrado en unas ricas minas. En su ausencia, Río de Janeiro es atacada y sitiada por los piratas franceses. La toma de la ciudad deja destrucción y víctimas, en cuenta el esposo de la condesa, quien muere durante las sangrientas luchas. La crónica revela cómo, en el pasado, Duclerc y Doña Garza habían tenido una intensa aventura amorosa mientras vivían en Versalles. De hecho, el francés había encabezado aquella incursión francesa a Río de Janeiro con el solo propósito de recuperar a la dama florentina. $Y$, efectivamente, tras la invasión, el francés caribeño y la italiana se reconcilian y retoman su amorío.

Al regreso de su misión, el jesuita Jean de Jouquières descubre que Aida y el capitán Duclerc están juntos de nuevo y se ve a sí mismo «con el alma despedazada por los celos, con una horrible sed de venganza» (Lima Barreto, 1997, p. 81). ${ }^{x x}$ En un arrebato de furia, el jesuita se traslada por los pasadizos secretos subterráneos y llega hasta el dormitorio de los amantes. Con un cuchillo en la mano, se dirige al lecho, donde apuñala y mata a Duclerc. Este avance despierta y aterroriza a Doña Garza, quien confronta al jesuita. En el cara a cara, la condesa le asegura que ella amaba al corsario y no a él. Por esta razón el jesuita arremete contra la noble y la hiere de muerte. Al día siguiente, según la crónica, se difunde por todo Río de Janeiro la noticia del enigmático asesinato del corsario francés y la noble florentina.

El códice dice que el crimen se convierte en un misterio, ya que el autor de las muertes nunca es capturado. Pero en la ciudad comienzan a circular rumores por una extraña coincidencia: el mismo día del sangriento crimen, en su celda del colegio jesuita, encuentran el cuerpo inerte del padre Jean de Jouquières, Marqués de Fressenec y, junto a él, un frasco de veneno y un puñal ensangrentado. El texto 
cierra así: «Aquí termina el manuscrito» (Lima Barreto, 1997, p. 97).xi Así acaba también la serie de crónicas del Correio da Manhã, ya que después de este episodio no aparecen más entregas que den seguimiento, ni sobre los otros documentos del señor Coelho ni sobre lo que sucede con las excavaciones del Cerro del Castillo. Es un final abrupto que clausura literariamente las crónicas, dejando una elipsis, como si la invasión francesa y el trágico desenlace ocasionaran un mutismo, una afasia.

Resulta significativo que el relato enmarcado de Doña Garza tenga como clímax el asesinato de Duclerc, el «criollo», a manos de un europeo, un francés. Este detalle muestra una de las capas de significación del texto de Lima Barreto, ya que en el momento en que escribe esta serie, la cultura europea -sobre todo la francesa- está en apogeo en Río de Janeiro, y ejerce su influencia a través de la moda y los gustos de la élite, que impulsa el programa de «regeneración» y de reforma urbana, inspiradas en la París de Georges-Eugène Haussmann. Este auge se notaba no solo en el nuevo paisaje europeo, sino también en prácticas sociales comunes, por ejemplo, la costumbre que tenían muchos cariocas de la época, que cuando se cruzaban en el camino o se reunían en algún lugar convencional intercambiaban un «¡Viva Francia!» (Sevcenko, 2003, p. 52). La ciudad de Río de Janeiro está viviendo un profundo cambio estético, una especie de cirugía plástica, que está transformando la fachada de la ciudad eliminando los vestigios de la colonia, borrando la pobreza del nuevo espacio público y tachando las distintas manifestaciones de la cultura popular. A los ojos de Lima Barreto, la cultura francesa está imponiéndose sobre la cultura criolla, la ciudad es entonces una metáfora del antiguo códice de su relato, la ciudad es el nuevo «palimpsesto».

En aquel momento, el Correio da Manhã era un medio que apoyaba abiertamente la reforma urbana y tenía su sede en la Rua do Ouvidor, una de las calles preferidas por la élite de la ciudad. En la Rua do Ouvidor se respiraban aires europeos y a lo largo de la ella había «tiendas hasta el tope, atiborradas de compradores, sobre todo las casas de joyas: la clientela diaria de señoras

\section{(c) (i) (2)}

La Revista Estudios es editada por la Universidad de Costa Rica y se distribuye bajo una Licencia Creative Commons Atribución-NoComercial-CompartirIgual 3.0 Costa Rica. Para más información envíe un mensaje a 
lujosamente vestidas» (Taunay, 1894, p. 37). De ahí, que Lima Barreto tuvo que tener un cuidado especial para disimular y solapar con un «manto de invisibilidad» su oposición, ya que estaba haciendo una crítica al sistema desde el interior mismo. Esta estrategia de disimulo también ayudó el hecho de que la serie de crónicas saliera publicada sin firma.

En todo caso, Lima Barreto reafirmaría su posición crítica después de que dejó de trabajar en el Correio da Manhã, sobre todo con a partir del año 1909, cuando publicó su primera novela, Recordações do escrivão Isaías Caminha (Recuerdos del escribiente Isaías Caminha, en español), que a diferencia de su serie de crónicas, generó un escándalo y fue tomada por la élite intelectual, política y económica brasileña como una afrenta directa. Para Lima Barreto, la transición por la que pasa Río de Janeiro durante la reforma urbana genera un cambio de identidad topográfico, arquitectónico, social y cultural que provoca una muerte simbólica, la muerte de la cultura criolla, principalmente afrobrasileña y mestiza, la muerte de la diversidad humana y de la naturaleza local. Es significativo también que el personaje de Doña Garza, quien en el relato del códice es un símbolo de la belleza, afirme que ama al criollo. Es así como la voz de la belleza expresa abiertamente su pasión por la hibridez, por aquel que ha nacido en América, no en Europa. El misterio de las riquezas escondidas en la serie es una estrategia subliminal y subterránea del escritor, ya que Lima Barreto considera que en la ciudad sí hay un tesoro oculto, pero es invisible para la élite brasileña de la época. Para el autor, el tesoro es la geografía, las tradiciones, el habla y la cultura popular, el legado y el presente afrobrasileño[se recomienda el uso del término afrodescendiente], así como la rica diversidad híbrida y mestiza de Río de Janeiro.

\section{(c) (1)(2)}

La Revista Estudios es editada por la Universidad de Costa Rica y se distribuye bajo una Licencia Creative Commons Atribución-NoComercial-CompartirIgual 3.0 Costa Rica. Para más información envíe un mensaje a 


\section{Conclusión}

Durante las primeras dos décadas del siglo XX, la élite de Brasil aspira a transformar a Río de Janeiro para convertirla en una vitrina de alta cultura, al mismo tiempo que miles de inmigrantes pobres de Europa y antiguos esclavos de las plantaciones están inundando a la capital en busca de una vida mejor: como resultado esta emergente ciudad comercial es un sitio de tensión entre clases que se oponen sobre el curso del futuro del país (Meade, 1997, p. 5). Lima Barreto se muestra sorprendido por la rapidez con que las medidas están transformando a la ciudad y expresa que la metamorfosis «surgió como si hubiese sido obtenida por una mutación teatral» (1956c, p. 106).

En un artículo de opinión, Lima Barreto expresó: «iRemodelar a Río! ¿Pero cómo? Arrasando los cerros... Pero no será más Río de Janeiro, será cualquier ciudad» (1956a, p. 124).xxii Lima Barreto se oponía al derrumbamiento de edificios antiguos y de los cerros, porque además de su valor histórico allí vivían miles de cariocas de la clase obrera. Para Lima Barreto, esta intervención donde se reconfigura el perfil urbano, eliminando sus contornos voluptuosos, suavizando sus rasgos autóctonos y destruyendo espacios físicos y simbólicos de la memoria histórica era un atentado contra la identidad carioca. Para la élite brasileña de aquel entonces los dos modelos americanos a seguir eran Nueva York y Buenos Aires. Lima Barreto expresaba que el afán por seguir el patrón neoyorquino era una «imitación mala y sórdida de los Estados Unidos» (1956d, p. 122). Con respecto al patrón argentino escribiría:

La obsesión de Buenos Aires siempre nos perturbó el juicio de las cosas. La gran ciudad de La Plata tiene un millón de habitantes, la capital de Argentina tiene largas calles rectas, la capital de Argentina no tiene negros, por lo tanto, señores míos, Río de Janeiro, atravesada de montañas, debe tener calles rectas, Río de Janeiro, en un país de tres o cuatro grandes ciudades, necesita tener también un millón, Río de Janeiro, capital de un país que recibió durante casi tres siglos millones de negros, no debe tener negros (Lima Barreto, 2004b, p. 166). xxiii

\section{(ब) $(\Theta \odot$}

La Revista Estudios es editada por la Universidad de Costa Rica y se distribuye bajo una Licencia Creative Commons Atribución-NoComercial-CompartirIgual 3.0 Costa Rica. Para más información envíe un mensaje a 
Lima Barreto creía que la «obsesión» por Buenos Aires «perturbaba», es decir, alteraba el orden y confundía, pero a la vez avergonzaba (Dicionário Priberam, 2020b). La razón de esa «vergüenza» era racial y racista: la manera en que la élite estaba reconfigurando la urbe, como en el códice ficcional de su crónica, era la articulación de un palimpsesto, la imposición de un nuevo patrón sobre otro, borrando superficialmente al anterior. ¿Por qué esa «obsesión» por borrar las curvas naturales de la ciudad para volverlas rectas? ¿Por qué desconocer la presencia de millones de afrobrasileños y personas pobres para desplazarlas fuera la fachada del nuevo paisaje? Lima Barreto pide invertir más en proyectos sociales para revertir la pobreza y en lugar de avergonzarse defiende esas «imperfecciones» topográficas, así como las «impurezas» e hibridaciones raciales, religiosas, históricas, culturales y lingüísticas. De hecho, este escritor reivindica la «fala brasileira», el portugués local, es decir, aboga por el uso de la gramática y los coloquialismos brasileños, ya que en aquella época en Brasil, el portugués escrito que «debía» usarse era el peninsular, el portugués de Portugal. Es lo que Ángel Rama describe como una «disglosia», la existencia de dos tipos de códigos lexicales, por un lado, una lengua rígida pública de los intelectuales, que es la que se pone por escrito y, por otro, una lengua popular en constante transformación utilizada en las calles por la mayoría de la población (1984, p. 50)

De manera que con su escritura, Lima Barreto hace una operación en la que cierra una brecha lingüística entre el portugués que se habla en las calles de Río de Janeiro y el portugués escrito. Esta es una de sus rupturas, ya que rompe con la tradición literaria de Brasil, dejando de lado el academicismo elitista y, más bien, optando por un lenguaje que se sirve de lo cotidiano (Nolasco-Freire, 2005, p. 139). No es extraño entonces que sus contemporáneos, guiados por su admiración de la estética lusitana, lo criticaran aduciendo que tenía una prosa descuidada. Lima Barreto no solamente emplea el portugués «criollo», sino que experimenta con él, hibridando géneros y mezclando la ficción con la no ficción. De hecho, es muy 
ISSN 1659-3316

Diciembre 2020-Mayo 2021

Muñoz Solano Néfer

posible que su relato de Doña Garza sea también un producto de la hibridación y la relectura, ya que podría estar basado en un relato brasileño del siglo XIX que narraba supuestos amores, crímenes y secretos de los jesuitas. ${ }^{\text {xiv }}$

Desde la prensa alternativa, el escritor continuó criticando, pero ya no de una manera solapada sino de una manera abierta y directamente, la reforma urbana comenzada por Pereira Passos y continuada por su sucesor en la alcaldía, Carlos Sampaio. Lima Barreto llega a mofarse de Sampaio al crear en sus textos un personaje ficticio llamado el «doctor Encerrabodes», a quien catalogaba irónicamente como «O poderoso dr. Matamorros» («el poderoso doctor Matacerros») (2010, p. 438). En un artículo de prensa, Lima Barreto decía que Sampaio quería dividir a Río de Janeiro en «dos ciudades», una europea y la otra indígena» (2005a, p. 126). El escritor no dejó de denunciar la inequidad y la segregación en la transformación de la ciudad, y acusaba al gobierno de dedicar la mayoría de sus recursos para embellecer barrios privilegiados, como Copacabana, mientras que descuidaba a la mayoría pobre, quien vivía precariamente en asentamientos pobres, en los años en que comienza a configurarse uno de los fenómenos sociales más conocidos de Brasil, las «favelas». El Cerro del Castillo fue demolido en su totalidad entre los años 1920 y 1922. Justo en medio, en el año 1921, Lima Barreto -quien contaba con 41 años- falleció, marcado por el alcoholismo y las enfermedades mentales.

\section{(C) $(00$}

La Revista Estudios es editada por la Universidad de Costa Rica y se distribuye bajo una Licencia Creative Commons Atribución-NoComercial-CompartirIgual 3.0 Costa Rica. Para más información envíe un mensaje a 


\section{Notas}

' En este artículo se presentan traducciones del português al español propias. Este fragmento, en el original en portugués dice: «Anteontem, ao cair da noite, era grande a azáfama naquele trecho das obras. A turma de trabalhadores, em golpes isócronos brandiam os alviões contra o terreno multissecular, e a cada golpe, um bloco de terra negra se deslocava, indo rolar, desfazendo-se, pelo talude natural do terreno revolvido. Em certo momento, o trabalhador Nelson, ao descarregar com pulso forte a picareta sobre as últimas pedras de um alicerce, notou com surpresa que o terreno cedia, desobstruindo a entrada de uma vasta galeria» (Lima Barreto, 1997, p. 3).

ii El «Dr. Rocha Leão» al que se refiere la noticia era el periodista y novelista «José Rocha Leão», quien en el año 1878 había publicado, bajo el pseudónimo de Leo Junius, un libro titulado Os subterrâneos do morro do Castelo, un texto que novelaba acontecimientos históricos sobre supuestos amores, crímenes y secretos de los jesuitas en Río de Janeiro (Kessel, 2008, p. 53). En la noticia, Lima Barreto cita tanto a Leo Junius como a Rocha Leão sin aclarar que son la misma persona.

iii En el original en portugués: «Pelo que vêem, eis aí farta messe de assunto para os amadores de literatura fantástica e para os megalômanos, candidatos a um aposento na Praia da Saudade» (Lima Barreto, 1997, p. 5).

iv Lima Barreto es un autor clásico de las letras brasileñas y es considerado uno de los principales escritores de América Latina. Sin embargo, solo una pequeña parte de su obra ha sido traducida al español, razón por la cual es poco difundido en el mundo hispanohablante.

` En el portugués original: «uma rematada tolice» (Lima Barreto, 1956a, p. 110).

vi Estas capitales-puerto, en los cincuenta años que siguen a 1880 duplican o triplican su población: la entonces capital brasileña pasa de tener 550 mil habitantes al comienzo del siglo XX a más de un millón de personas para el año 1920 (Romero, 1999, p. 300).

vii En el original en portugués: «Mas justamente porque tanto te ama, é que teu filho deve ter o direito de te dizer, entre dous beijos, que a vizinhança de Buenos Aires é uma vergonha para ti, adorada Sebastianópolis» (Bilac, 1900, p. 2).

viii En 1853, Napoleón III nombra a Haussmann prefecto de Siena, encargándole la "modernización" de la capital francesa, que a partir de entonces vive un proceso de

\section{(C) $(\Theta \odot$}

La Revista Estudios es editada por la Universidad de Costa Rica y se distribuye bajo una Licencia Creative Commons Atribución-NoComercial-CompartirIgual 3.0 Costa Rica. Para más información envíe un mensaje a 
reestructuración y rediseño que incluyó amplias avenidas, bulevares comerciales, jardines fastuosos, edificios monumentales y una altitud uniforme en el perfil citadino. En aras de la nueva estética de París, la "haussmanización" es casi una intervención "quirúrgica" que cobra como víctimas barrios enteros antiguos que son arrasados, en un proceso que algunos críticos describen como "vandalismo" del pasado (Carmona, 2002, p. 432), y que además, provoca el desplazamiento de los asentamientos pobres hacia las afueras de los límites oficiales de la ciudad. Sin embargo, a pesar de las críticas, París se convierte en un modelo de ciudad comercial, "moderna" y burguesa y comienza a tener una enorme influencia en los planes de reforma urbana alrededor del mundo.

ix «Bota-abaixo» o «tirar abajo» es la expresión popular que en la época circula entre la población de Río de Janeiro para describir las demoliciones y la reforma urbana que se realizó en la capital federal. El término inspira al novelista José Vieira a escribir, en 1904, una crónica sobre la reforma urbana que titula precisamente $O$ bota-abaixo.

x En el original en portugués: «Há poucos dias, as picaretas, entoando un hino jubiloso, iniciaram os trabalhos da Avenida Central... No aluir das paredes, no ruir das pedras, no esfarelar do barro, havia um longo gemido. Era o gemido soturno e lamentoso do Passado, do Atraso, do Opróbio. A cidade colonial, imunda, retrógrada, emperrada nas suas velhas tradições, estava soluçando no soluçar daqueles apodrecidos materiais que desabavam. Mas o hino claro das picaretas abafava esse protesto impotente» (2002, p. 353).

xi En 1852 surge una tesis presentada por el médico Domingos Martins Guerra, quien sostenía la necesidad de demoler el Morro do Castelo y el Morro de Santo Antonio pues la ciudad necesitaba de aire, de circulación, del soplo ininterrumpido de los vientos marinos (Kessel, 2008, p. 36).

xii En el original en portugués: «no maior desconforto, imundície e promiscuidade, pronta para armar em barricadas as vielas estreitas do Centro ao som do primeiro grito de motim» (Sevcenko, 2003, p. 41).

xiii A Lima Barreto le molestaba también la tendencia periodística de dar prioridad a las noticia policiales, que hacían que los diarios parecieran "morgues", por el gran número de fotografías de cadáveres que publicaban (2005b, p. 265). Más bien, Lima Barreto abogaba para que los periódicos brasileños le dieran más espacio a temas políticos y literarios, así como de administración pública y asuntos internacionales. En su opinión, el periodismo debía dar importancia a los temas públicos y no a los privados, a lo colectivo que beneficiara a las mayorías y no a lo individual ni a los intereses de una minoría elitista.

\section{(c) (1) 8 (2)}

La Revista Estudios es editada por la Universidad de Costa Rica y se distribuye bajo una Licencia Creative Commons Atribución-NoComercial-CompartirIgual 3.0 Costa Rica. Para más información envíe un mensaje a 
xiv Benchimol explica cómo la palabra "embellecer" cobra una enorme importancia en la propaganda política de la época.

xv En el original en portugués:

«-Então, já foram descobertos os apóstolos?

-Que apóstolos?

-Os de ouro, com olhos de esmeralda?

-Por ora não, respondeu-nos risonho o engenheiro e, solícito, acompanhou-nos à porta da galeria.

Esta é alta, de 1 metro e 90 centímetros, com cerca de 80 centímetros de largura; no interior operários retiravam o barro mole e pegajoso, atolados no lameiro até o meio das canelas. Ao fundo bruxuleava uma luzinha dúbia, posta ali para facilitar a desobstrução do subterrâneo. Um cenário tétrico de dramalhão» (Lima Barreto, 1997, p. 8).

xvi En el original en portugués: «Amanhã contaremos aos leitores esta bizarra e maravilhosa história» (Lima Barreto, 1997, p. 28).

xvii La palabra «folletín», diminutivo de folleto, viene del latín «folium», que significa «hoja» (González de Gambier, 2002, p. 169). Este género tiene sus antecedentes en la prensa francesa del siglo XIX: el «feuilleton» era una sección especial de los periódicos franceses donde se publicaban trabajos extensos que, por sus dimensiones, aparecían de forma fragmentada y podían ser ensayos, críticas de libros, relatos de viajes o libros de memorias (Diccionario de literatura española e hispanoamericana, 1993, p. 568). Más adelante, el género se consolidó como una publicación de novelas por entregas, dada la periodicidad de los diarios.

xviii En el portugués original es: «D. Garça ou o que se passou em meados do século XVIII, nos subterrâneos dos padres da Companhia de Jesus, na cidade de S. Sebastião do Rio de Janeiro, a mui heroica, por ocasião da primeira invasão dos franceses a mando de Clerc» (Lima Barreto, 1997, p. 36).

xix Aquí hay una inconsistencia en el relato, porque en una entrega previa se había informado a los lectores que los jesuitas habían ocultado sus riquezas en sus subterráneos después de la invasión de Duclerc, no antes. Este tipo de inconsistencias y descuidos son propios de la literatura de folletín, que siempre se escribía con la premura por la presión del cierre del diario (González de Gambier, 2002, p. 168).

xx En el original en portugués: «com a alma despedaçada pelo ciúme, numa sede horrível de vingança» (Lima Barreto, 1997, p. 81).

\section{(c) (i) (2)}

La Revista Estudios es editada por la Universidad de Costa Rica y se distribuye bajo una Licencia Creative Commons Atribución-NoComercial-CompartirIgual 3.0 Costa Rica. Para más información envíe un mensaje a 
xxi En el original en portugués: «Aqui termina o manuscrito» (Lima Barreto, 1997, p. 97).

xxii En el original en portugués: «Remodelar o Rio! Mas como? Arrasando os morros... Mas não será mais o Rio de Janeiro; será toda outra qualquer cidade» (1956a, p. 124).

xxiii En el original en portugués: «A obsessão de Buenos Aires sempre nos perturbou o julgamento das coisas. A grande cidade do Prata tem um milhão de habitantes; a capital da Argentina tem longas ruas retas; a capital Argentina não tem pretos; portanto, meus senhores, o Rio de Janeiro, cortado de montanhas, deve ter largas ruas retas; o Rio de Janeiro, num país de três ou quatro grandes cidades, precisa ter um milhão; o Rio de Janeiro, capital de um país que recebeu durante quase três séculos milhões de pretos, não deve ter pretos» (Lima Barreto, 2004b, p. 166).

xxiv La novela en la que pudo basarse Lima Barreto para sus crónicas es Os subterrâneos do morro do Castelo de Leo Junius, el pseudónimo del periodista y novelista José Rocha Leão Este libro utiliza acontecimientos históricos para narrar de forma novelada los amores, crímenes y secretos de los jesuitas. Especialmente, cita el caso de una hidalga portuguesa, Doña Maria de Gusmão, secuestrada y llevada a Brasil, donde es encerrada en uno de los calabozos subterráneos del colegio. En su cautiverio, Gusmão da a luz a un hijo, cuyo padre es uno de los jesuitas superiores.

\section{Bibliografía}

Aidoo, L., \& Silva, D. F. (2013). Introduction. En Lima Barreto: New Critical Perspectives (pp. 1-8). Lexington Books.

Arciniegas, G. (2002). América: 500 años de un nombre: vida y época de Amérigo Vespucci (3. ed). Villegas Editores.

Barbosa, F. de A. (2003). Prefácio. En Literatura como missão: Tensões sociais e criação cultural na Primeira República (pp. 15-20). Companhia das Letras.

Barros, P. C. de. (2002). Onde nasceu a cidade do Rio de Janeiro? (Um pouco da história do Morro do Castelo). Revista geo-paisagem, 1(2).

Benchimol, J. L. (1990). Pereira Passos: Um Haussmann tropical: a renovação urbana da cidade do Rio de Janeiro no início do século XX. Secretaria Municipal de Cultura, Turismo e Esportes, Departamento Geral de Documentação e Informação Cultural, Divisão de Editoração.

\section{(c) (P) 8 (9)}

La Revista Estudios es editada por la Universidad de Costa Rica y se distribuye bajo una Licencia Creative Commons Atribución-NoComercial-CompartirIgual 3.0 Costa Rica. Para más información envíe un mensaje a revistaestudios.eeg@ucr.ac.cr. 
Bilac, O. (1900, noviembre 18). Crônica. Gazeta de Notícias.

Bilac, O. (2002). Bilac, o jornalista (Vol. 2). EDUSP: Imprensa Oficial; Editora Unicamp.

Carmona, M. (2002). Haussmann: His Life and Times, and the Making of Modern Paris (P. Camiller, Trad.). I.R. Dee.

Dealtry, G. F. (1999). Lima Barreto-Os subterrâneos de uma nação. Revista Escrita, 4, 51-68.

Diccionario de literatura española e hispanoamericana. (1993). Alianza Editorial.

Dicionário Priberam. (2020a). Megalomania. En Dicionário Priberam. https://dicionario.priberam.org/megalomania

Dicionário Priberam. (2020b). Perturbar. En Dicionário Priberam. https://dicionario.priberam.org/perturbar

Dicionário Priberam. (2020c). Regeneração. En Dicionário Priberam. https://dicionario.priberam.org/regeneração

Gomes, R. C. (2008). Todas as cidades, a cidade: Literatura e experiência urbana (2a. edição, revista e ampliada). Rocco.

González, A. (2006). Periodismo y novela en Hispanoamérica: La ley del disimulo en Amalia de José Mármol y Tomochic de Heriberto Frías. Revista Iberoamericana, 72(214), 227-242.

González de Gambier, E. (2002). Diccionario de terminología literaria. Editorial Síntesis.

Goodman, N. (1978). Ways of Worldmaking. Hackett Pub. Co.

Gramsci, A. (1999). Cuadernos de la cárcel: Vol. VI (A. M. Palos, Trad.). Era, BUAP.

Kessel, C. (2008). Tesouros do Morro do Castelo: Mistério e história nos subterrâneos do Rio de Janeiro. Zahar.

Lima Barreto. (1909). Recordações do escrivão Isaías Caminha. Livraria Classica Editora de A. M. Teixeira \& Cta.

Lima Barreto. (1956a). Coisas do reino do Jambon (Vol. 8). Editôra Brasiliense.

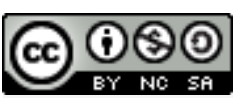

La Revista Estudios es editada por la Universidad de Costa Rica y se distribuye bajo una Licencia Creative Commons Atribución-NoComercial-CompartirIgual 3.0 Costa Rica. Para más información envíe un mensaje a revistaestudios.eeg@ucr.ac.cr. 
Lima Barreto. (1956b). Impressões de leitura (Vol. 13). Editôra Brasiliense.

Lima Barreto. (1956c). Os Bruzundangas: Sátira (Vol. 7). Editôra Brasiliense.

Lima Barreto. (1956d). Vida urbana; artigos e crônicas (Vol. 11). Editôra Brasiliense.

Lima Barreto. (1993). O destino da literatura. En Um longo sonho do futuro: Diários, cartas, entrevistas e confissões dispersas (pp. 384-395). Graphia Editorial.

Lima Barreto. (1997). O Subterrâneo do Morro do Castelo: Um folhetim de Lima Barreto (B. Resende, Ed.; 2a ed.). Dantes Livraria Editora.

Lima Barreto. (2004a). Lima Barreto (I. Travancas, Ed.). Nova Fronteira.

Lima Barreto. (2004b). Toda crônica: 1890-1919 (B. Resende \& R. Valença, Eds.). Agir Editora.

Lima Barreto. (2005a). Lima Barreto (B. Resende, Ed.). Global.

Lima Barreto. (2005b). Os nossos jornais. En B. Resende (Ed.), Lima Barreto. Global.

Lima Barreto. (2010). Contos completos. Companhia das Letras.

Mahieux, V. (2011). Urban Chroniclers in Modern Latin America: The Shared Intimacy of Everyday Life. University of Texas Press.

Martínez, T. E. (2004). Ficción historia, periodismo: Límites y márgenes. Revista Digital Telar - Universidad de Tucumán, 37-54.

Meade, T. A. (1997). Civilizing Rio: Reform and Resistance in a Brazilian City, 18891930. Pennsylvania State University Press.

Meade, T. A. (2010). A Brief History of Brazil. Infobase Publishing.

Meyer, M. (1996). Folhetim: Uma história. Companhia das Letras.

Mignolo, W. (1987). Cartas, crónicas y relaciones del descubrimiento y la conquista. En Historia de la literatura hispanoamericana: Vol. Tomo 1 (pp. 57-116). Cátedra.

Moreira, P. (2013). Climbing the Social Ladder as a Tragic Farce in Brazil at the Turn of the Century. En L. Aidoo \& D. F. Silva (Eds.), Lima Barreto: New Critical Perspectives (pp. 97-115). Lexington Books.

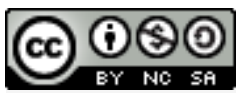

La Revista Estudios es editada por la Universidad de Costa Rica y se distribuye bajo una Licencia Creative Commons Atribución-NoComercial-CompartirIgual 3.0 Costa Rica. Para más información envíe un mensaje a revistaestudios.eeg@ucr.ac.cr. 
Nolasco-Freire, Z. (2005). Lima Barreto, imagem e linguagem. Annablume. O Rio de Janeiro de Pereira Passos. (1985). Editora Index.

Prefeitura da cidade do Rio de Janeiro. (2006). Pereira Passos, vida e obra. Secretaria Municipal de Urganismo, Instituto Pereira Passos, Diretoria de Informações Geográficas.

Rama, Á. (1984). La ciudad letrada. Ediciones del Norte.

Resende, B. (1993). Lima Barreto e o Rio de Janeiro em fragmentos. Editora UFRJ; Editora da Unicamp.

Romero, J. L. (1999). Latinoamérica, las ciudades y las ideas. Editorial Universidad de Antioquia.

Schwarcz, L. M. (2010). Introdução-Lima Barreto: Termômetro nervoso de uma frágil República. En Contos completos de Lima Barreto (pp. 15-54). Companhia das Letras.

Sevcenko, N. (2003). Literatura como missão: Tensões sociais e criação cultural na Primeira República. Companhia das Letras.

Taunay, A. d'Escragnolle T. (1894). O encilhamento; scenas contemporaneas da bolsa em 1890, 1891 e 1892. D. de Magalhães.

Travancas, I. (2004). Notas. En Lima Barreto. Nova Fronteira.

Vasconcellos, E. (2001). Nota editorial. En Prosa Seleta (pp. 11-15). Editora Nova Aguilar.

Vejmelka, M. (208d. C.). Uma arqueologia do Rio. Escavando O Subterrâneo do Morro do Castelo de Lima Barreto. En Ensaios premiados: A obra de Lima Barreto (pp. 175-211). Ministério das Relações Exteriores, Departamento Cultural.

Wasserman, R. (2011). The Press in Novels: Credit, Power and Movility in William D. Howell's Modern Instance and Lima Barreto's Recordações do escrivão Isaias Caminha. Comparative Literature Studies, 48(1), 44-63. https://doi.org/Article

\footnotetext{
(c) (1) (2)

La Revista Estudios es editada por la Universidad de Costa Rica y se distribuye bajo una Licencia Creative Commons Atribución-NoComercial-CompartirIgual 3.0 Costa Rica. Para más información envíe un mensaje a revistaestudios.eeg@ucr.ac.cr.
} 